\title{
USABILITY TESTING PADA APLIKASI POTWIS
}

\author{
Tifani Yuliyana ${ }^{1}$, I Ketut Resika Arthana ${ }^{1}$, Ketut Agustini ${ }^{1}$ \\ Program Studi Pendidikan Teknik Informatika, UniversitasPendidikan Ganesha, Bali, Indonesia \\ Email: tifaniyuliyana.012pti@gmail.com
}

\begin{abstract}
Abstrak
Penelitian ini dilakukan untuk mengevaluasi aplikasi POTWIS dengan menyoroti tiga konsep usability yaitu efektivitas, efisiensi, dan kepuasan pengguna dalam menggunakan aplikasi POTWIS diukur menggunakan metode Usability Testing teknik Performance Measurement, RTA, UEQ, dan SUS. Tujuannya ialah untuk mengetahui hasil usability testing dan rekomendasi perbaikan pada aplikasi POTWIS berdasarkan hasil usability testing.

Hasil penelitian ini berdasarkan analisis dari perhitungan statistik Mann Whitney $U$ Test, UEQ dan SUS menunjukkan bahwa (1) aplikasi POTWIS belum efektif dilihat dari adanya kesalahan yang dilakukan oleh responden saat pengerjaan tugas, (2) aplikasi POTWIS sudah efisien dilihat dari waktu pengerjaan tugas karena tidak ada perbedaan yang signifikan waktu pengerjaan tugas responden kelompok mahir dan kelompok pemula, (3) aplikasi POTWIS belum memenuhi skala efisiensi diukur menggunakan UEQ dengan skor sebesar 0.625 dinyatakan masih dibawah rata-rata, dan (4) aplikasi POTWIS belum memenuhi kepuasan pengguna dilihat dari skor SUS sebesar 53.00 yang dinyatakan masih dibawah skor rata-rata yaitu $>68$.
\end{abstract}

Kata kunci: usability, POTWIS, SUS, UEQ, wireframe.

\section{Abstract}

This research was conducted to evaluate POTWIS application by highlighting three usability concepts that effectiveness, efficiency, and the satisfaction of the user in using POTWIS application measured by usability testing methode, Performance Measurement, RTA, UEQ, and SUS technique. The purpose is to know the result of usability testing and improvement recommendation on POTWIS application based of the result of usability testing.

The result of this research is based on analysis of statical calculation Mann Whitney U Test, UEQ dan SUS which showed (1) POTWIS application is not effective seen from the existance of the mistake made by respondent during the task, (2) POTWIS application is efficient seen from the time of task execution because the execution time between proficient group and beginner group was not significantly different, (3) POTWIS application has not met the scale of efficiency measured by UEQ with score 0.625 which showed below the average and (4) POTWIS application has not fulfilled user satisfaction measured by SUS with score 53.00 which is stated still below the average score is $>68$.

Keywords: usability, POTWIS, SUS, UEQ, wireframe.

\section{PENDAHULUAN}

Aplikasi POTWIS bermanfaat untuk menginformasikan potensi atau objek wisata yang diketahui dan menampilkan objek wista. Aplikasi POTWIS memanfaatkan teknologi LBS (Location-Based Services) untuk memberikan informasi dalam bentuk peta, objek wisata terdekat dan rute menuju objek wisata tersebut. Aplikasi POTWIS dirancang dengan mengadopsi konsep Crowdsourcing dimana konten, tanggapan dan penilaian diberikan oleh masyarakat (Arthana Resika, Setemen, Purnamawan, \&
Andiani, 2016). Aplikasi POTWIS diharapkan dapat menjadi fasilitas pendukung masyarakat yang ingin berwisata. Namun, hingga saat belum pernah dilakukan evaluasi dari tingkat usability, sehingga belum diketahui apakah aplikasi POTWIS telah memenuhi kriteria usability yaitu efektivitas, efisiensi, dan kepuasan pengguna.

Usability berasal dari Bahasa Inggris yaitu usable yang secara umum berarti dapat digunakan dengan baik. Sesuatu dapat dikatakan berguna dengan baik apabila kegagalan dalam penggunaannya dapat 
dihilangkan atau diminimalkan serta memberi manfaat dan kepuasan kepada pengguna (Rubin, J., \& Chisnell, 2008). Suatu aplikasi disebut usable jika fungsifungsinya dapat dijalankan secara efektif, efisien, dan memuaskan (Nielsen, 1993).

Evaluasi usability adalah proses yang melibatkan pengguna sehingga dapat mempelajari dan menggunakan produk guna tercapainya aspek-aspek kenyamanan pengguna seperti efektivitas, efisiensi, dan kepuasan pengguna terhadap sistem secara keseluruhan (U.S. Department of Health \& Human Services, 2014).

Menurut Zaphiris \& Kurniawan, metode evaluasi usability dapat dikategorikan menjadi model/metrics based, inspection, inquiry, dan testing (Utama, 2011). Diantara keempat kategori metode tersebut yang saat ini paling banyak digunakan untuk menguji sebuah sistem karena lebih akurat adalah metode usability testing (Utami, 2016). Sehingga dalam penelitian ini metode yang digunakan adalah usability testing, dimana metode ini digunakan untuk mengobservasi pengguna saat berinteraksi dengan aplikasi POTWIS.

Usability testing memiliki beberapa teknik evaluasi yang berbeda. Diantara beberapa teknik dalam usability testing terdapat teknik dengan mengukur performa keberhasilan dan kecepatan pengerjaan task (tugas) yaitu teknik Performance Measurement. Selain itu, ada teknik RTA (Retrospective Think Aloud) dimana teknik ini memungkinkan responden menceritakan perasaan, pikiran, dan pendapatnya saat berinteraksi dengan aplikasi. Kedua teknik tersebut lebih mudah digunakan dan dapat mengukur aspek penting dalam usability, yaitu efektivitas, efisiensi, dan kepuasan pengguna. Oleh karena itu, dalam penelitian ini teknik yang digunakan ialah teknik Performance Measurement dan RTA.

Pentingnya melakukan usability testing pada aplikasi mobile dibuktikan dengan adanya penelitian yang dilakukan oleh Gatsou et al., pada tahun 2013 lalu denga judul penelitian "Exploring Inexperienced User Performance of a Mobile Tablet Application Through Usability Testing". Setelah dilakukan usability testing pada pengguna diperoleh aspek yang perlu ditingkan yaitu efektivitas dan mengurangi terjadinya kesalahan yang dilakukan oleh pengguna, serta didapatkan hasil berupa nilai kepuasan pengguna yang diukur dengan kuesioner SUS yang nantinya dapat dijadikan acuan dalam aspek kepuasan pengguna.

Penelitian lain yang dilakukan oleh Azzahra et al., tahun 2015 dengan judul penelitian "Usability Evaluation of Mobile Application in Culinary Recommendation System". Setelah melakukan evaluasi usability pada pengguna diperoleh aspekaspek penting dalam mengukur learnability, efektivitas, dan kepuasuan pengguna, yang diukur dengan teknik CTA (Concurent Think Aloud) dan kuesioner SUS.

Selain itu berdasarkan penelitian yang dilakukan oleh Satria Utama pada tahun 2011, yang berjudul "Perbaiakn User Interface Halaman Internet Banking dengan Metode Usability Testing", menunjukkan setelah dilakukannya perbaikan user interface halaman Internet Banking dapat menjadikan user interface lebih efektif, efisien, dan meningkatkan kepuasan pengguna yang didapatkan dari hasil evaluasi usability dengan teknik Eye Tracking, Performance Measurement, dan RTA.

Berdasarkan permasalahan yang dipaparkan tersebut, maka penulis hendak melakukan penelitian yang berjudul "Usability Testing pada Aplikasi POTWIS" dengan tujuan mengevaluasi aplikasi POTWIS pada aspek usability menggunakan teknik usability testing dengan teknik Performance Measurement, RTA, UEQ, dan Kuesioner SUS. Selain itu, dari hasil usability testing ini diharapkan dapat memberikan sebuah rekomendasi perbaikan aplikasi POTWIS.

\section{METODE}

\section{A. Aplikasi POTWIS}

Aplikasi POTWIS bermanfaat untuk menginformasikan potensi atau objek wisata yang diketahui dan menampilkan objek wista. Aplikasi POTWIS memanfaatkan teknologi LBS (Location-Based Services) untuk memberikan informasi dalam bentuk peta, objek wisata terdekat dan rute menuju 
objek wisata tersebut. Aplikasi POTWIS dirancang dengan mengadopsi konsep Crowdsourcing dimana konten, tanggapan dan penilaian diberikan oleh masyarakat (Arthana Resika et al., 2016).

Adapun halaman-halaman yang terdapat pada aplikasi POTWIS adalah halaman login, halaman daftar objek wisata, informasi detail objek wisata, rute menuju lokasi objek wisata, komentar dan rating pada objek wisata, menambah dan melihat foto objek wisata, menambah atau mengedit konten objek wisata, melaporkan konten objek wisata, menambah, objek wisata baru, peta seluruh tempat objek wisata.

\section{B. Usability}

Istilah usability sering digunakan dalam bidang Human Computer Interaction $(\mathrm{HCl})$ (Gatsou, Politis, \& Zevgolis, 2013). Human Computer Interaction yaitu sebagai interaksi komputer manusia, adalah multi disiplin ilmu yang fokus pada desain, evaluasi dan implementasi dari interaksi sistem yang digunakan oleh manusia dan hal lain yang berada di sekitar (Saifulloh \& Asnawi, 2015). Usability berasal dari Bahasa Inggris yaitu usable yang secara umum berarti dapat digunakan dengan baik. Sesuatu dapat dikatakan berguna dengan baik apabila kegagalan dalam penggunaannya dapat dihilangkan atau diminimalkan serta memberi manfaat dan kepuasan kepada pengguna (Rubin, J., \& Chisnell, 2008). Suatu aplikasi disebut usable jika fungsifungsinya dapat dijalankan secara efektif, efisien, dan memuaskan (Nielsen, 1993).

Usability didefinisikan oleh 5 komponen berkualiatas yaitu learnability, efficiency, memorability, error, satisfaction (Nielsen, 2012). ISO 9241-11 mengatakan usability memiliki 3 dimensi yaitu efektivitas, efisiensi dan kepuasan (ISO 9241-11, 1998).

Menurut Zaphiris \& Kurniawan, metode evaluasi usability dapat dikategorikan menjadi model/metrics based, inspection, inquiry, dan testing (Utama, 2011). Dalam penelitian ini menggunakan metode Testing. Usability testing adalah teknik yang digunakan untuk mengevaluasi produk dengan mengujinya langsung pada pengguna (Nalurita, Yogasara, \& Hariandja, 2015). Usability testing mempunyai beberapa teknik evaluasi yang berbeda yaitu teknik Think Aloud dibagi menjadi dua CTA (Concurent Think Aloud) dan RTA (Restrospective Think Aloud), Shadowing Method, Coaching Method, Question-Asking Protocol, Teaching Method, Performance Measurement, Remote Testing, dan Eye Tracker. Dalam penelitian ini, peneliti menggunakan teknik Performance Measurement dan teknik RTA.

\section{B.1 Performance Measurement}

Teknik ini digunakan untuk memperoleh data kuantitatif terkait kinerja peserta tes ketika melakukan tugas selama pengujian usability. Teknik ini umumnya melarang interaksi antara peserta dan evaluator selama uji yang akan mempengaruhi data kinerja kuantitatif. Data kuantitatif sangat berguna dalam melakukan pengujian perbandingan waktu pengerjaan untuk melihat efisiensi dan membandingkan jumlah error untuk melihat efektifitas.

\section{B.2 Retrospective Think Aloud (RTA)}

Teknik evaluasi RTA dilakukan ketika responden selesai melakukan interaksi dengan sistem. Responden akan diminta memverbalisasi pikiran, perasaan, dan pendapatnya dengan bantuan melihat media video yang memutar kembali aktifitas yang dilakukan responden saat berinteraksi dengan sistem.

\section{UEQ (User Experience Questionnaires)}

Tujuan utama dari penggunaan kuesioner UX adalah untuk memungkinkan pengukuran cepat dan segera pengalaman pengguna produk interaktif (Laugwitz, Held, \& Schrepp, 2008). UEQ telah diterapkan dalam berbagai konteks penelitian, misalnya untuk evaluasi perangkat lunak bisnis (Rauschenberger, Hinderks, \& Thomaschewski, 2011), alat-alat pengembangan (Wieschnowsky \& Paulheim, 2011), situs web dan layanan web (Hartmann, 2011), atau jaringan sosial (Hartmann, 2011).

Item penilaian UEQ diwujudkan sebagai diferensial semantik, yaitu masingmasing item penilaian diwakili oleh sepasang istilah dengan arti yang berlawanan. Urutan istilah diacak per item, yaitu setengah dari 
item dari skala awal dengan istilah positif dan setengah lainnya dari item dimulai dengan istilah negatif. UEQ menggunakan skala tujuh tahap untuk mengurangi terkenanya bias tendensi sentral untuk jenis seperti barang.

UEQ mengandung 6 pertimbangan dengan total 26 item penilaian. Struktur skala UEQ adalah sebagai berikut.

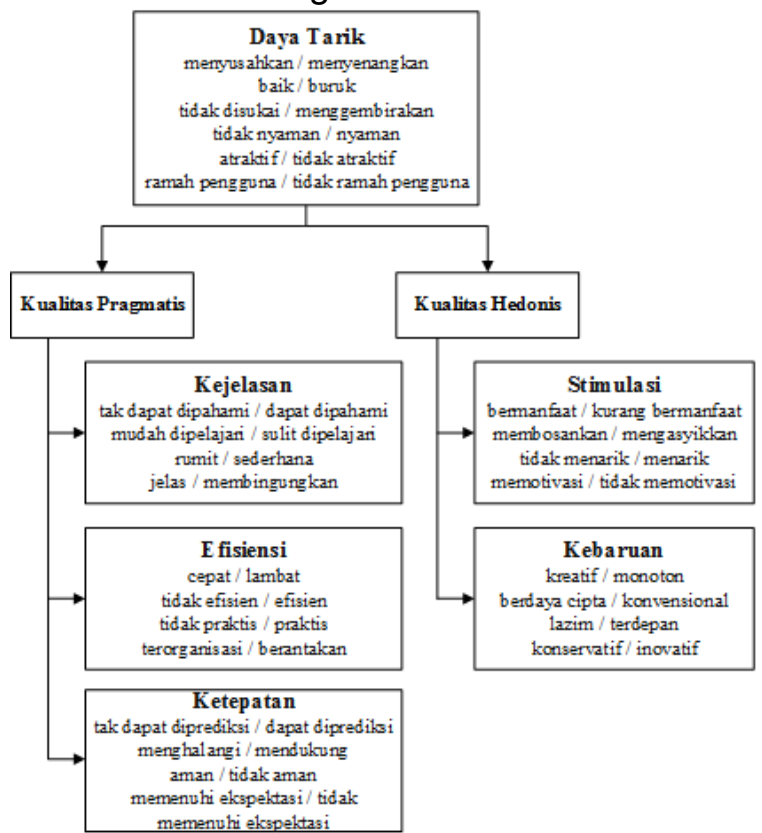

Gambar 1 Struktur Skala UEQ

Sumber : (Schrepp, 2015)

\section{SUS (System Usability Scale)}

SUS merupakan sebuah kuesioner yang mengacu pada Standard Usability Questionnaires. SUS dikenal sebagai pengukur kepuasan pengguna yang "quick and dirty" artinya penggunaan kuesioner SUS sangat cepat dan data yang dihasilkan dapat dipercaya. Kuesioner SUS paling sering digunakan untuk mengukur persepsi usability (Sauro, 2011). SUS juga merupakan paket usability testing (pengujian kebergunaan) yang efektif dan handal untuk digunakan pada berbagai produk dan aplikasi (Bangor, Kortum, \& Miller, 2009).

\section{E. Uji Statistik Mann Whitney U Test}

Mann Whitney $U$ test adalah sebuah uji statistik non parametrik yang digunakan untuk membandingkan dua kelompok independen (berbeda partisipan dalam setiap kelompoknya) (Utama, 2011). Asumsi yang berlaku dalam Mann Whitney $U$ test yaitu (1) sampel yang berasal dari populasi adalah acak, (2) sampel bersifat independen, dan (3) skala pengukuran yang digunakan adalah ordinal (Utama, 2011). Dalam penelitian ini menggunakan nilai a (alpha) 0.05 .

\section{F. Responden}

Literatur tidak memberikan jumlah responden optimal yang jelas dalam melakukan usability testing. Nielsen (Nielsen, 2000) berpendapat bahwa 5 responden atau partisipasi akan menemukan $80 \%$ dari masalah suatu sistem. Faulkner (Faulkner, 2003) berpendapat bahwa 5 orang hanya akan menemukan sebanyak $55 \%$ permasalahan usability, untuk mendapatkan $90 \%$ permasalahan dalam usability maka diperlukan sebanyak minimal 15 orang, dan untuk mendapatkan 95\% permasalahan dalam usability maka diperlukan sebanyak minimal 20 orang pengguna.

Dalam penelitian Gatsou et al. (2013) dengan judul penelitian "Exploring Inexperienced User Performance of a Mobile Tablet Application Through Usability Testing" menggunakan 12 peserta partisipasi. Sedangkan penelitian yang dilakukan oleh Az-zahra et al. (2015) dengan judul penelitian "Usability Evaluation of Mobile Application in Culinary Recommendation System" menggunakan 5 peserta partisipasi. Oleh sebab itu, peneliti menggunakan 20 responden yang dijadikan sampel untuk melakukan usability testing pada aplikasi POTWIS, dimana responden tersebut dikelompokkan menjadi kelompok pemula dan kelompok mahir.

\section{G. Wireframe}

Wireframes dapat dibuat secara manual dengan tangan atau dengan menggunakan perangkat lunak, seperti Balsamiq (Junus, Santoso, Isal, \& Utomo, 2015). Wireframes yang dibuat dalam penelitian ini adalah gambar rangka sederhana yang menyediakan gambar mengenai tata letak dan memberikan informasi atau fungsi yang lebih rinci mengenai perbaikan rekomendasi halaman antarmuka sistem aplikasi POTWIS dengan menggunakan perangkat lunak Balsamiq Mockups 3. 


\section{HASIL DAN PEMBAHASAN}

Untuk mengukur efektivitas pada aplikasi POTWIS yakni mengetahui error yang dilakukan oleh responden pada tiap tugas yang diberikan. Sedangkan efisiensi diukur dari hasil data waktu pengerjaan tugas kemudian akan dibandingkan antara responden kelompok pemula dan kelompok mahir dengan menggunakan uji statistik, dan untuk mengukur efisiensi juga digunakan perhitungan UEQ. Untuk mengukur kepuasan pengguna yakni dengan melakukan rekapitulasi hasil kuisioner dan dianalisis dengan perhitungan SUS.

Data yang diperoleh dari proses usability testing dengan teknik Performance Measurement diperoleh hasil data waktu pengerjaan tugas terhadap 20 responden mahasiswa. Sedangkan data yang didapat dari proses usability testing dengan teknik RTA diperoleh hasil data berupa data masalah atau kesulitan saat menggunakan aplikasi serta saran dari responden yang menunjukkan kesulitan atau masalah yang dialami responden ketika menggunakan aplikasi POTWIS.

Dari hasil analisis data responden mengalami kesalahan (error) saat mengerjakan tugas $4,5,6,7,10,11,12,13$, dan tugas 14.

Tabel 1 Data Penyebab Kesalahan (Error) Responden

\begin{tabular}{|c|c|c|}
\hline Tugas & $\begin{array}{l}\text { Kode } \\
\text { Respo } \\
\text { nden }\end{array}$ & Penyebab Error \\
\hline 4 & $\begin{array}{l}\text { RP02, } \\
\text { RM02 }\end{array}$ & $\begin{array}{l}\text { Setelah klik lihat objek } \\
\text { wisata secara detail, } \\
\text { responden langsung } \\
\text { terfokus pada rating } \\
\text { bintang dibawah } \\
\text { gambar utama objek } \\
\text { wisata dan mencoba } \\
\text { mengklik beberapa kali } \\
\text { tetapi tidak } \\
\text { menunukkan adanya } \\
\text { respon dari aplikasi, } \\
\text { maka responden } \\
\text { langsung melanjutkan } \\
\text { pada tugas selanjutnya } \\
\text { sehingga r tidak } \\
\text { menemukan r menu } \\
\text { Rating dan Komentar. }\end{array}$ \\
\hline
\end{tabular}

\begin{tabular}{|c|c|c|}
\hline 5 & RP04 & $\begin{array}{l}\text { Sudah masuk pada } \\
\text { Tampilan Lihat Semua } \\
\text { Gambar Objek Wisata, } \\
\text { responden tidak tahu } \\
\text { dimana letak tombol } \\
\text { untuk meng-upload } \\
\text { gambar, responden } \\
\text { hanya mengklik } \\
\text { Refresh, setelah itu } \\
\text { responden langsung } \\
\text { melanjutkan pada } \\
\text { tugas selanjutnya } \\
\text { sehingga tidak } \\
\text { menemukan tombol } \\
\text { untuk Upload gambar. }\end{array}$ \\
\hline 6 & RP08 & $\begin{array}{l}\text { Setelah klik icon menu } \\
\text { Edit dan Tambah } \\
\text { Deskripsi } \\
\text { Wisata, maka keluar } \\
\text { tampilan Pilih Konten } \\
\text { Yang Diedit. Namun } \\
\text { pada bagian ini } \\
\text { responden merasa } \\
\text { ragu untuk mengklik } \\
\text { karena pada pada } \\
\text { tampilannya responden } \\
\text { membaca } \\
\text { beranggapan hanya } \\
\text { diperuntukkan "untuk } \\
\text { konten yang diedit } \\
\text { saja" sehingga } \\
\text { responden melanjutkan } \\
\text { pada tugas berikutnya. }\end{array}$ \\
\hline 7 & $\begin{array}{l}\text { RP08 } \\
\text { RM09 }\end{array}$ & $\begin{array}{l}\text { Tugas } 7 \text { tidak dibaca } \\
\text { (terlewati). } \\
\text { Responden sudah klik } \\
\text { icon tombol Lapor } \\
\text { Objek Wisata, akan } \\
\text { tetapi proses } \\
\text { menampilkannya } \\
\text { lumayan lama maka } \\
\text { responden } \\
\text { memutuskan untuk ke } \\
\text { tugas selanjutnya. }\end{array}$ \\
\hline 10 & $\begin{array}{l}\text { RP05, } \\
\text { RP07 }\end{array}$ & $\begin{array}{lr}\text { Saat responden } \\
\text { memasukkan alamat } \\
\text { pada kolom Masukkan } \\
\text { Alamat Objek Wisata, } \\
\text { responden tidak } \\
\text { menyedari bahwa } \\
\text { setelah itu perlu lagi di } \\
\text { klik tombol Search } \\
\text { dibagian pojok kanan }\end{array}$ \\
\hline
\end{tabular}

Jurnal Sains dan Teknologi | 16 


\begin{tabular}{|c|c|c|}
\hline & & $\begin{array}{l}\text { kolom Memasukkan } \\
\text { Alamat Objek Wisata, } \\
\text { sehingga responden } \\
\text { langsung Next pada } \\
\text { tahap selanjutnya. }\end{array}$ \\
\hline 11 & $\begin{array}{l}\text { RP01, } \\
\text { RP02, } \\
\text { RP04, } \\
\text { RP05, } \\
\text { RP06, } \\
\text { RP07, } \\
\text { RP08, } \\
\text { RP10, } \\
\text { RM02, } \\
\text { RM07, } \\
\text { RM10 }\end{array}$ & $\begin{array}{l}\text { Ketika responden } \\
\text { melakukan pencarian } \\
\text { objek wisata yang telah } \\
\text { ditambahkan, namun } \\
\text { responden } \\
\text { kebingungan karena } \\
\text { objek wisata yang telah } \\
\text { ditambahkan tidak ada } \\
\text { atau tidak tampil saat } \\
\text { dicari pada kolom } \\
\text { Search. Jadi, disini } \\
\text { responden belum } \\
\text { memahami bahwa } \\
\text { ketika melakukan } \\
\text { Pencarian objek wisata } \\
\text { aplikasi POTWIS } \\
\text { hanya bisa membaca } \\
\text { satu keyword (satu } \\
\text { suku kata) saja. }\end{array}$ \\
\hline 12 & $\begin{array}{l}\text { RP01, } \\
\text { RP02, } \\
\text { RP,04, } \\
\text { RP05, } \\
\text { RP06, } \\
\text { RP08, } \\
\text { RP10, } \\
\text { RM02, } \\
\text { RM03, } \\
\text { RM07, } \\
\text { RM10 }\end{array}$ & $\begin{array}{lr}\text { Karena objek } & \text { wisata } \\
\text { yang } & \text { telah } \\
\text { ditambahkan } & \text { tidak } \\
\text { ditemukan } & \text { melalui } \\
\text { pencarian di } & \text { kolom } \\
\text { Search dan sudah } \\
\text { mencari secara manual } \\
\text { semampunya maka } \\
\text { tugas 12 ini dilewati } \\
\text { oleh user. }\end{array}$ \\
\hline 13 & $\begin{array}{l}\text { RP01, } \\
\text { RP02, } \\
\text { RP,04, } \\
\text { RP05, } \\
\text { RP06, } \\
\text { RP08, } \\
\text { RP10, } \\
\text { RM02, } \\
\text { RM07, } \\
\text { RM10 }\end{array}$ & $\begin{array}{lr}\text { Karena objek } & \text { wisata } \\
\text { yang } & \text { telah } \\
\text { ditambahkan } & \text { tidak } \\
\text { ditemukan } & \text { melalui } \\
\text { pencarian di } & \text { kolom } \\
\text { Search dan sudah } \\
\text { mencari secara manual } \\
\text { semampunya maka } \\
\text { tugas 13 ini dilewati } \\
\text { oleh user. }\end{array}$ \\
\hline 14 & RM04 & $\begin{array}{l}\text { Tugas } 14 \text { tidak dibaca } \\
\text { (terlewati). }\end{array}$ \\
\hline
\end{tabular}

Data analisis yang didapat dari proses usability testing dengan teknik Performance Measurement dan Retrospective Think Aloud (RTA), sebagai berikut :

a. Efektivitas
Untuk menganalisis dan mengukur efektivitas diukur dengan melihat terjadinya Error yang terjadi saat responden menyelesaikan tugas. Mmaka diperoleh data terjadinya kesalahan (error) responden pada Tabel 2 berikut.

Tabel 2 Data Kesalahan Penggunaan (Error) Responden

\begin{tabular}{|c|c|c|c|c|}
\hline Kelompok & Tugas & $\begin{array}{c}\text { Jumlah } \\
\text { Responden }\end{array}$ & $\begin{array}{c}\text { Jumlah } \\
\text { Error }\end{array}$ & $\begin{array}{c}\text { Presentase } \\
\text { Jumlah } \\
\text { Error }\end{array}$ \\
\hline \multirow[t]{14}{*}{ Pemula } & Tugas 1 & 10 & 0 & $0.00 \%$ \\
\hline & Tugas 2 & 10 & 0 & $0.00 \%$ \\
\hline & Tugas 3 & 10 & 0 & $0.00 \%$ \\
\hline & Tugas 4 & 10 & 1 & $10.00 \%$ \\
\hline & Tugas 5 & 10 & 1 & $10.00 \%$ \\
\hline & Tugas 6 & 10 & 1 & $10.00 \%$ \\
\hline & Tugas 7 & 10 & 1 & $10.00 \%$ \\
\hline & Tugas 8 & 10 & 0 & $0.00 \%$ \\
\hline & Tugas 9 & 10 & 0 & $0.00 \%$ \\
\hline & Tugas 10 & 10 & 0 & $0.00 \%$ \\
\hline & Tugas 11 & 10 & 8 & $80.00 \%$ \\
\hline & Tugas 12 & 10 & 7 & $70.00 \%$ \\
\hline & Tugas 13 & 10 & 7 & $70.00 \%$ \\
\hline & Tugas 14 & 10 & 1 & $10.00 \%$ \\
\hline \multirow[t]{14}{*}{ Mahir } & Tugas 1 & 10 & 0 & $0.00 \%$ \\
\hline & Tugas 2 & 10 & 0 & $0.00 \%$ \\
\hline & Tugas 3 & 10 & 0 & $0.00 \%$ \\
\hline & Tugas 4 & 10 & 1 & $10.00 \%$ \\
\hline & Tugas 5 & 10 & 0 & $0.00 \%$ \\
\hline & Tugas 6 & 10 & 0 & $0.00 \%$ \\
\hline & Tugas 7 & 10 & 1 & $10.00 \%$ \\
\hline & Tugas 8 & 10 & 0 & $0.00 \%$ \\
\hline & Tugas 9 & 10 & 0 & $0.00 \%$ \\
\hline & Tugas 10 & 10 & 0 & $0.00 \%$ \\
\hline & Tugas 11 & 10 & 3 & $30.00 \%$ \\
\hline & Tugas 12 & 10 & 4 & $40.00 \%$ \\
\hline & Tugas 13 & 10 & 3 & $30.00 \%$ \\
\hline & Tuqas 14 & 10 & 0 & $0.00 \%$ \\
\hline
\end{tabular}

Dengan terdapatnya error beserta penyebabnya pada proses penyelesaian task skenario (tugas) tersebut, dapat disimpulkan bahwa halaman aplikasi POTWIS dikatakan belum efektif.

\section{b. Efisiensi}

Untuk mengukur efisiensi pengerjaan tugas dilakukan dengan membandingkan waktu pengerjaan responden pemula dengan responden mahir pada hasil pengukuran usability aplikasi POTWIS menggunakan Mann Whitney U-test. Hipotesis yang digunakan tiap tugas adalah sebagai berikut:

- H0: Tidak ada perbedaan waktu pengerjaan tugas $(x)$ pada responden kelompok pemula dan kelompok mahir.

- H1 : Ada perbedaan waktu pengerjaan tugas $(x)$ pada responden kelompok pemula dan kelompok mahir.

Pada hasil data responden, nilai pvalue dari masing-masing tugas terdapat pada Tabel 3 berikut.

Tabel 3 Nilai $p$-value Data Responden Jurnal Sains dan Teknologi | 17 


\begin{tabular}{|c|c|}
\hline Tugas & p-value \\
\hline Task 1 & 0.029 \\
\hline Task 2 & 0.140 \\
\hline Task 3 & 0.068 \\
\hline Task 4 & 0.130 \\
\hline Task 5 & 0.494 \\
\hline Task 6 & 0.472 \\
\hline Task 7 & 0.404 \\
\hline Task 8 & 0.317 \\
\hline Task 9 & 0.677 \\
\hline Task 10 & 0.596 \\
\hline Task 11 & 0.031 \\
\hline Task 12 & 0.281 \\
\hline Task 13 & 0.146 \\
\hline Task 14 & 0.412 \\
\hline
\end{tabular}

Secara statistik dari 14 tugas dapat dinyatakan tidak ada perbedaan yang signifikan, naum tugas 1 dan 11 menunjukkan perbedaan yang signifikan, meskipun waktu pengerjaan tugas responden kelompok mahir sedikit lebih cepat dari kelompok pemula. Maka dapat diputuskan bahwa halaman aplikasi POTWIS sudah efisien dilihat dari waktu pengerjaan tugas.

Sedangkan dilihat dari skala Efisiensi yang diukur menggunakan kuesioner UEQ perolehan nilai rata responden sebesar 0.625 . Hal ini berarti nilai skor tersebut dibawah rata-rata, sehingga dapat dikatakan bahwa aplikasi POTWIS belum memenuhi faktor efisiensi UEQ. Serta terdapatnya hasil pengukuran skala UEQ lainnya (Daya Tarik, Kejelasan, Ketepatan, Stimulasi, dan Kebaruan aplikasi POTWIS).

Tabel 4 Rekapitulasi Nilai Skala UEQ

\begin{tabular}{|l|c|l|}
\hline \multicolumn{1}{|c|}{ Skala } & Rata-rata & Perbandingan dengan tolok ukur \\
\hline Daya tarik & 1.133333333 & Dibawah rata-rata \\
\hline Kejelasan & 1 & Dibawah rata-rata \\
\hline Efisiensi & 0.625 & Dibawah rata-rata \\
\hline Ketepatan & 0.8875 & Dibawah rata-rata \\
\hline Stimulasi & 1.125 & Diatas rata-rata \\
\hline Kebaruan & 0.95 & Diatas rata-rata \\
\hline
\end{tabular}

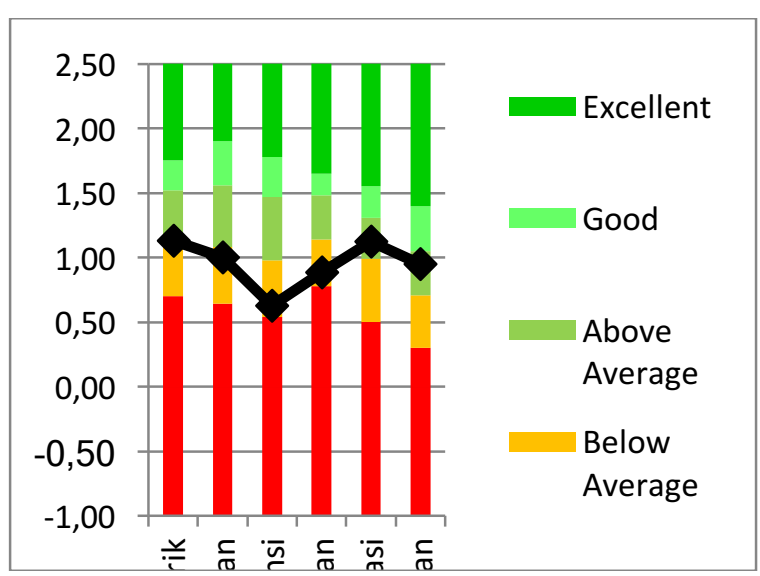

Gambar 2 Tingkat Pencapaian Berdasarkan Hasil Uji Lapangan

\section{c. Kepuasan Pengguna}

Perolehan nilai skor responden kuesioner SUS sebesar 53.00. Hal ini berarti nilai skor tesrsebut lebih kecil dari skor standar SUS yaitu 68. Sehingga dapat dikatakan bahwa responden kurang puas menggunakan aplikasi POTWIS. Dilihat dari data kuesioner yang diperoleh pernyataan yang memiliki nilai terendah adalah pengguna merasa memerlukan bantuan orang lain ketika menggunakan aplikasi POTWIS, dan responden menemukan fitur yang sangat rumit digunakan pada aplikasi POTWIS.

Dari hasil yang didapatkan maka rekomendasi perbaikan dilakukan dengan membuat wireframe, dimana dasar yang digunakan untuk mengembangkan rekomendasi adalah panduan $\mathrm{HCl}$ dan hasil data usability testing yaitu performance measurement dan RTA. Berdasarkan hasil performance measurement, rekomendasi perbaikan dalam penelitian ini akan difokuskan pada tata letak (layout) halaman dan menu navigasi sesuai hasil data penyebab kesalahan (error) pengguna sesuai dengan data penyebab kesalahan (error) pengguna, serta saran pengguna melalui hasil RTA yaitu menyederhanakan menu, konsistensi kejelasan button, konsistensi penggunaan bahasa dan istilah untuk setiap button, serta rekomendasi perbaikan fungsionalitas. Berikut adalah halaman aplikasi POTWIS hasil rekomendasi perbaikan.

1. Rekomendasi perbaikan Halaman Utama Aplikasi POTWIS 
Gambar 3 Halaman Utama dan Wireframe Rekomendasi

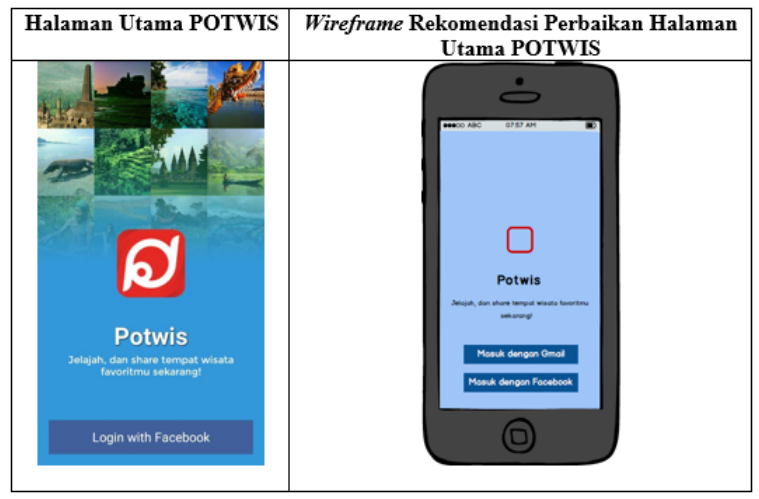

Rekomendasi perbaikan halaman utama POTWIS yang dilakukan adalah bahasa yang digunakan setiap button aplikasi POTWIS, menambahkan button masuk ke aplikasi POTWIS menggunakan akun Google.

2. Rekomendasi Perbaikan Halaman Beranda

Gambar 4 Halaman Beranda dan Wireframe Rekomendasi

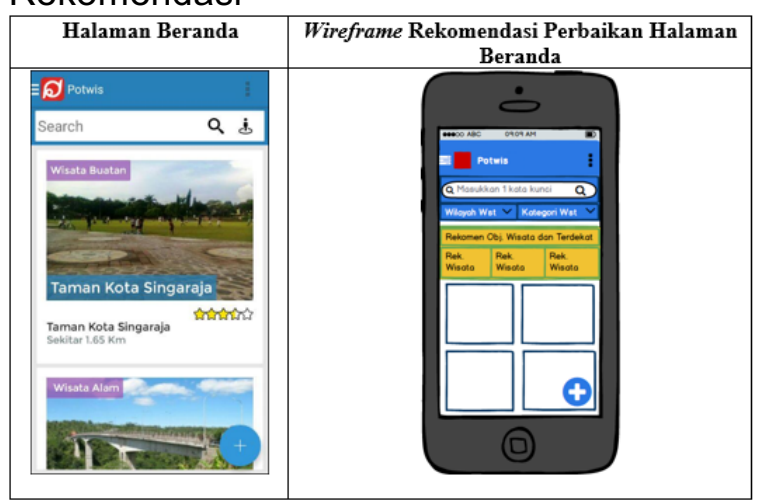

Rekomendasi perbaikan halaman Beranda POTWIS adalah perbaikan pada form pencarian dengan memasukkan sebuah keterangan pada kolom pencarian, menghilangkan button yang berfungsi untuk menampilkan objek wisata terdekat user, menambah menu filter berdasarkan wilayah objek wisata dan kategori wisata, serta perbaikan pada segi fungsionalitas agar aplikasi POTWIS memastikan kembali terkait dengan keabsahan data objek wisata yang diinput user.

3. Rekomendasi Perbaikan Halaman Lihat Detail Objek Wisata
Gambar 5 Halaman Lihat Detail Objek Wisata dan Wireframe Rekomendasi Halaman Utama POTWIS Wireframe Rekomendasi Perbaikan Halaman

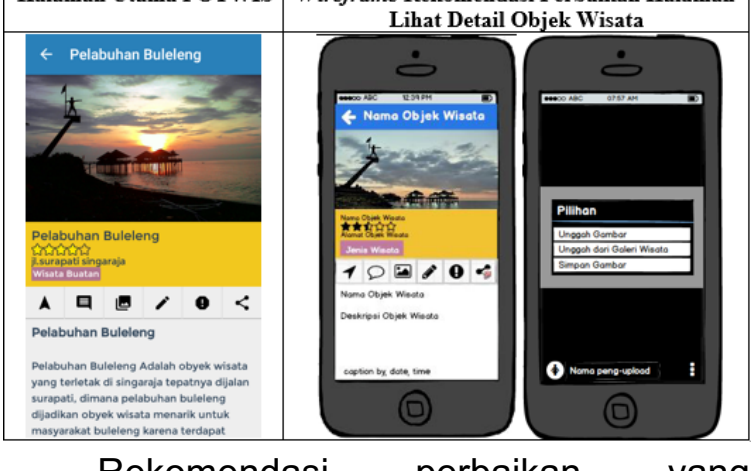

Rekomendasi

perbaikan

yang

dilakukan adalah gambar sampul bisa di klik, terdapat opsi pilihan untuk mengganti gambar sampul objek wisata dan menyimpan gambar sampul objwk wisata, serta perbaikan pada fungsionalitas dimana ketika responden sudah mendapatkan berupa pesan berhasil mengganti gambar sampul objek wisata, namun sebenarnya gambar sampul objek wisata tidak terganti (tidak ada perubahan).

4. Rekomendasi Perbaikan Halaman Komentar

Gambar 6 Halaman Komentar dan Wireframe Rekomendasi

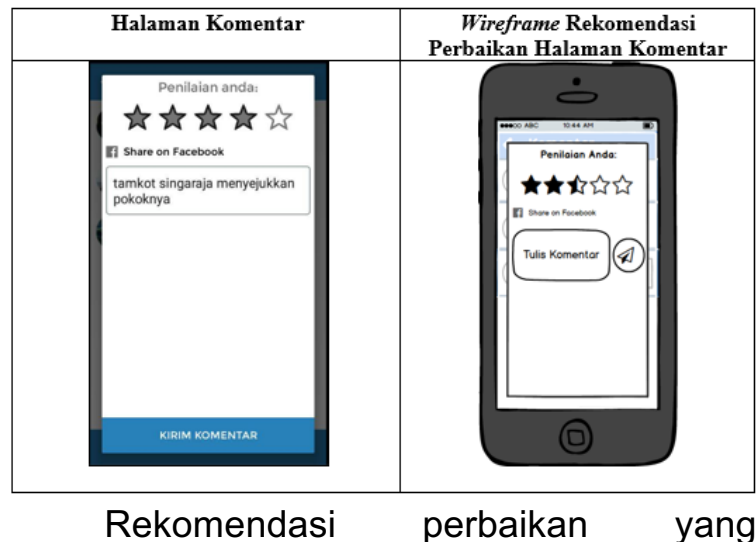

dilakukan adalah memindahkan tombol Kirim Komentar di sebelah kolom Tulis Komentar.

5. Rekomendasi Perbaikan Halaman Lihat Galeri Gambar Objek Wisata 
Gambar 7 Halaman Lihat Galeri Gambar Objek Wisata dan Wireframe Rekomendasi

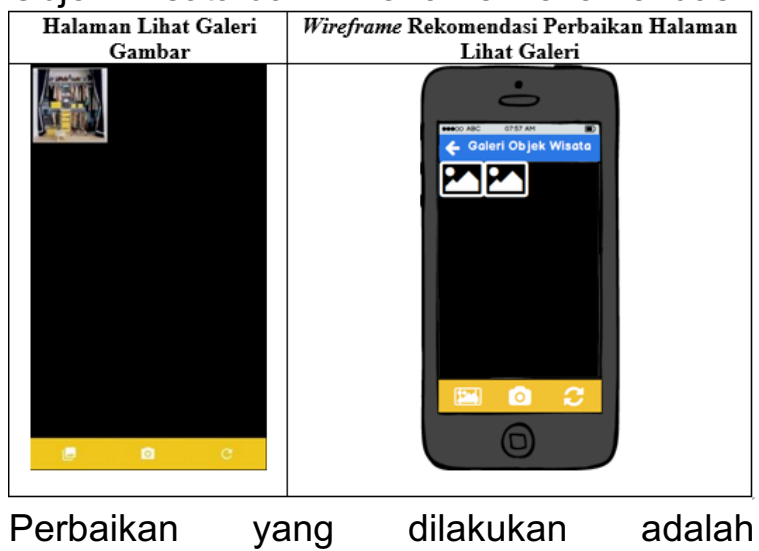

menambahkan berupa keterangan nama halaman yang sedang dibuka, dan adanya tombol Kembali (back).

6. Rekomendasi Perbaikan Halaman Share

Gambar 8 Halaman Berbagi (share) dan wireframe Rekomendasi

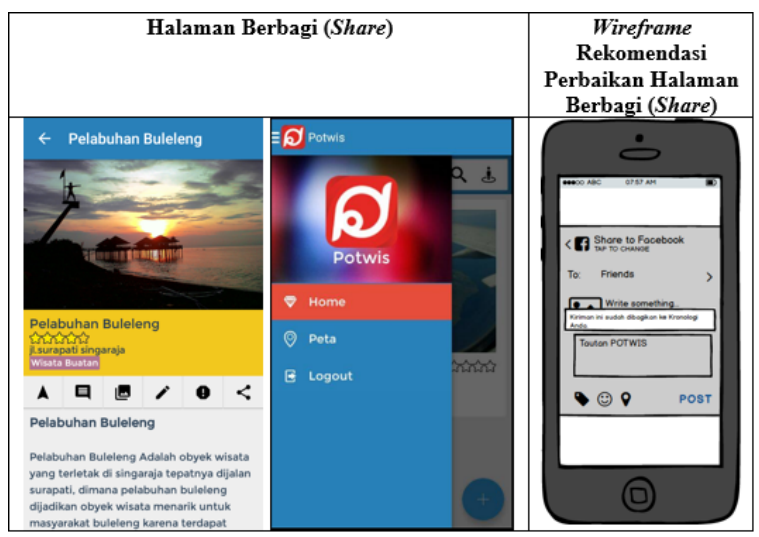

Perbaikan yang dilakukan adalah menambah pesan berupa tautan berhasil di Bagikan (share) atau tidak, dan tersedianya tampilan yang digunakan untuk menulis keterangan (caption) sebelum tautan objek wisata di bagikan (share).

7. Rekomendasi Perbaikan Halaman

Menambah Alamat Objek Wisata Baru
Gambar 9 Halaman Menambah Alamat Objek Wisata Baru dan Wireframe Rekomendasi

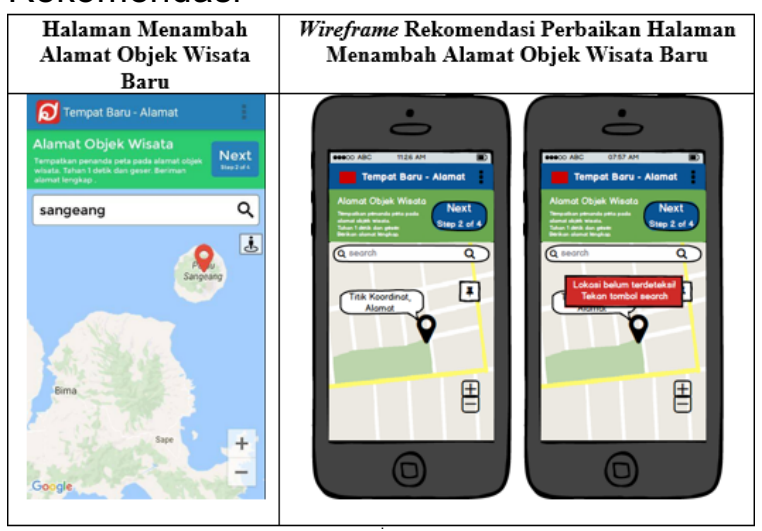

Perbaikan yang dilakukan adalah ketika meletakkan/menggeser penanda peta pada titik yang dimaksud maka akan langsung terdeteksi titik koordinat dan alamat lokasi yang diberi tanda, serta pada kolom Pencarian bisa digunakan untuk mencari alamat objek wisata berdasarkan titik koordinat. Selain itu, menaambahkan pesan berupa syarat untuk bisa lanjut pada step berikutnya.

8. Rekomendasi Perbaikan Halaman Seluruh Peta Objek Wisata

Gambar 10 Halaman Seluruh Peta Objek Wisata dan Wireframe Rekomendasi

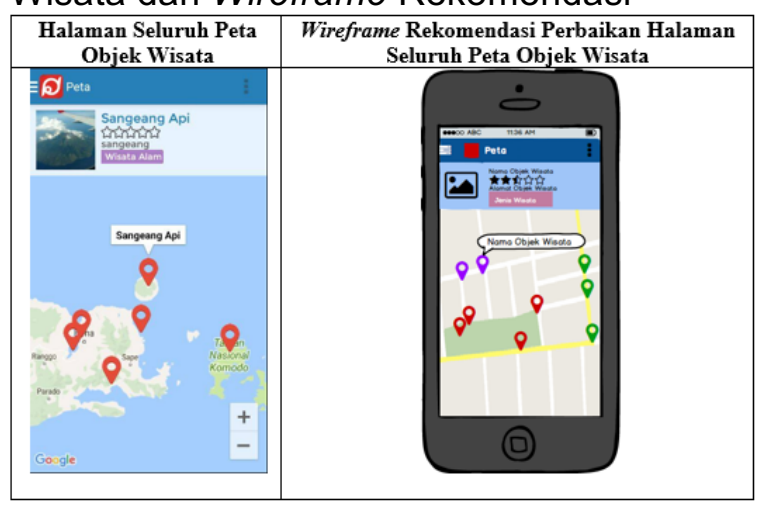

Rekomendasi perbaikan yang dilakukan adalah mengubah warna penanda peta berdasarkan kategori objek wisata, dan menambahkan berupa tombol Kembali (back) yang berfungsi untuk kembali ke halaman sebelumnya.

9. Rekomendasi Perbaikan Halaman Menu Aplikasi POTWIS 
Gambar 11 Halaman Menu POTWIS dan Wireframe Rekomendasi

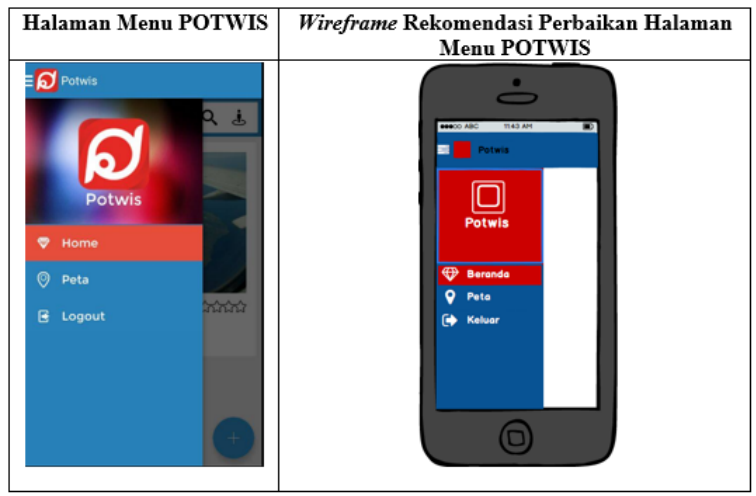

Perbaikan yang dilakukan adalah perubahan bahasa yang digunakan pada tombol Home menjadi Beranda, tombol Logout menjadi Keluar. Konsistensi penggunaan bahasa ini dibataskan pada tombol aplikasi POTWIS saja. Perbaikan lainnya adalah terkait fungsionalitas tombol Logout agar diperjelas, apakah berfungsi keluar dari akun yang digunakan untuk masuk ke aplikasi POTWIS, atau menutup aplikasi POTWIS. Hal ini dilakukan berdasarkan kritik dari responden untuk kejelasan menu/tombol Logout.

\section{SIMPULAN}

Berdasarkan hasil penelitian yang dilakukan terkait usability testing pada aplikasi POTWIS dapat disimpulkan bahwa (1) halaman aplikasi POTWIS secara umum belum efektif karena terjadi error dalam pengerjaan tugas oleh responden (2) dilihat dari hasil data yang didapat dengan teknik performance measurement diketahui bahwa secara statistik waktu pengerjaan tugas responden pemula secara signifikan hampir sama dengan responden mahir, walaupun mean rank untuk kelompok mahir lebih cepat, sehingga halaman aplikasi POTWIS sudah efisien, (3) dari data skala efisiensi kuesioner UEQ diperoleh hasil sebesar 0.625 dikatakan masih dibawah rata-rata, sehingga aplikasi POTWIS belum efisiensi dari segi kuesioner UEQ, dan (4) dari data kepuasan responden yang didapat dari hasil kuesioner SUS diketahui bahwa skor yang diperoleh kurang dari 68 yaitu sebesar 53.00 , sehingga responden dikatakan merasa kurang puas menggunakan aplikasi POTWIS.
Hasil yang didapat dari proses usability testing diketahui bahwa halaman aplikasi POTWIS tidak memenuhi kriteria sebuah produk dengan usability yang baik. Hal ini dapat dilihat pada penilaian tingkat efektivitas, efesiensi, dan kepuasan pengguna, halaman aplikasi POTWIS tidak mampu memenuhi kriteria yang baik untuk ketiga aspek tersebut.

Rekomendasi perbaikan dalam penelitian ini difokuskan untuk mengubah tata letak (layout) halaman dan memenuhi menu navigasi sesuai hasil data penyebab kesalahan (error) pengguna, menyederhanakan menu, kejelasan button, konsistensi penggunaan bahasa dan istilah untuk setiap button, serta rekomendasi perbaikan fungsionalitas aplikasi POTWIS sesuai dengan data penyebab kesalahan (error) pengguna. Perbaikan dilakukan dengan membuat wireframe rekomendasi halaman utama POTWIS, halaman home, halaman lihat detail objek wisata, halaman lihat foto sampul objek wisata, halaman komentar, halaman lihat galeri foto objek wisata, halaman lihat detail foto objek wisata, halaman share objek wisata, halaman menambah alamat objek wisata baru, halaman seluruh peta objek wisata, halaman menu aplikasi POTWIS, fungsionalitas logout, serta fungsionalitas keterpercayaan data objek wisata.

\section{SARAN}

Sebaiknya dilakukan penyesuaian design aplikasi POTWIS agar terlihat menarik, dan untuk penelitian selanjutnya perlu ditambahkan metode untuk mengukur aspek usability lainnya, yaitu learnability dan memorability, sehingga hasil penelitian lebih detail mengenai variabel apa saja yang perlu mendapat perhatian.

\section{DAFTAR PUSTAKA}

Arthana Resika, I. K., Setemen, K., Purnamawan, I. K., \& Andiani, N. D. (2016). Penggalian dan Penyebaran Potensi Wisata melalui Aplikasi Mobile dengan Konsep Crowdsourcing. JPTK, 13(1), 111-126.

Bangor, A., Kortum, P., \& Miller, J. (2009). Determining What Individual SUS Scores Mean: Adding an Adjective 
Rating Scale. Journal of Usability Studies, 4(3), 114-123. Retrieved from http://dl.acm.org/citation.cfm?id=28355 89

Faulkner, L. (2003). Beyond the five-user assumption: Benefits of increased sample sizes in usability testing. Behavior Research Methods, Instruments \& Computers, 35(3), 379383.

https://doi.org/10.3758/BF03195514

Gatsou, C., Politis, A., \& Zevgolis, D. (2013). Exploring inexperienced user performance of a mobile tablet application through usability testing. Computer Science and ..., 557-564.

Hartmann, J. (2011). User Experience Monitoring: Über die Notwendigkeit geschäftskritische Online-Prozesse permanent $\mathrm{zu}$ überwachen. I-Com, 10(3), 59-62. https://doi.org/10.1524/icom.2011.0035

ISO 9241-11. (1998). ISO 924111:1998(en), Ergonomic requirements for office work with visual display terminals (VDTs) - Part 11: Guidance on usability. Retrieved March 27, 2017, from

https://www.iso.org/obp/ui/\#iso:std:iso: 9241:-11:ed-1:v1:en

Laugwitz, B., Held, T., \& Schrepp, M. (2008). Construction and Evaluation of a User Experience Questionnaire. LNCS, 5298, 63-76. Retrieved from http://citeseerx.ist.psu.edu/viewdoc/do wnload?doi=10.1.1.472.3719\&rep=rep 1\&type=pdf

Nalurita, R., Yogasara, T., \& Hariandja, D. J. (2015). Evaluasi Metode dan Kriteria Usability Testing pada Aplikasi Mobile untuk Anak-Anak Sekolah Dasar di Indonesia. Seminar Nasional IENACO ,- 2337-4349.

Nielsen, J. (1993). Usability Engineering Jakob Nielsen - Paperback.

Nielsen, J. (2000). Why You Only Need to Test with 5 Users. Jakob Nielsens Alertbox, 19(September 23), 1-4. https://doi.org/http://www.useit.com/ale rtbox/20000319.html

Nielsen, J. (2012). Usability 101: Introduction to Usability. Nielsen Norman Group, Articles. https://doi.org/10.1145/1268577.12685 85

Rauschenberger, M., Hinderks, A., \& Thomaschewski, J. (2011). Benutzererlebnis bei Unternehmenssoftware: Ein Praxisbericht über die Umsetzung attraktiver Unternehmenssoftware. In Usability Professionals Konferenz 2011 (Vol. 1, p. pp--158). Retrieved from https://usability-bremen.de/wpcontent/uploads/2013/03/Rauschenber ger-Hinderks-et-al-2011-

Benutzererlebnis-beiUnternehmenssoftware.pdf

Rubin, J., \& Chisnell, D. (2008). Handbook of usability testing [electronic resource]: How to plan, design, and conduct effective tests (2nd ed.). Indianapolis, IN: Wiley Pub. https://doi.org/10.1007/s13398-0140173-7.2

Saifulloh, \& Asnawi, N. (2015). Data Manajemen Dan Teknologi Informasi. Jurnal IImiah DASI (Data Manajemen Dan Teknologi Informasi), 16(4), 5558. Retrieved from http://ojs.amikom.ac.id/index.php/dasi/ article/view/246/244

Sauro, J. (2011). MeasuringU: Mengukur Usability dengan Sistem Usability Skala (SUS). Retrieved March 3, 2017, from https://measuringu.com/sus/

Schrepp, M. (2015). User Experience Questionnaire Handbook. https://doi.org/10.13140/rg.2.1.2815.02 45

U.S. Department of Health \& Human Services. (2014). Usability evaluation basics, 6-7. Retrieved from http://www.usability.gov/what-andwhy/usability-evaluation.html

Utama, S. (2011). Perbaikan User Interface Halaman Internet Banking dengan Metode Usability Testing. SKRIPSI.

Wieschnowsky, T., \& Paulheim, H. (2011). A Visual Tool for Supporting Developers in Ontology-based Application Integration. 7th International Workshop on .... Retrieved from http://www.heikopaulheim.com/docs/s wese2011b.pdf 